\title{
Animals and Gender in Present - Day English
}

\author{
Ludmila Zemkova
}

\section{DOI: 10.18355/XL.2016.09.01.110-126}

\begin{abstract}
This paper is the contribution to gender studies providing an answer to the core question: "How is gender assigned to animal nouns in English?" In this analysis the focus is predominantly on gender in animals. The introductory part summarizes recent descriptions of gender assignment in animal nouns and looks at grammarians' treatment of "gender in present - day English".

A detailed analysis of gender assignment to animal names is based on zoological articles concerning animal species ranging from insects to apes. The corpus for this analysis includes all National Geographic articles concerning animal species published between 1979 and 2014.

Key words

gender markers, gender distinctions, animal nouns, National Geographic

\section{Introduction}

"The shift of gender is motivated by affect or emotion" (Vachek 1964:190).

The introductory part will look at grammarians' treatment of gender in PresentDay English. As Vachek notes, "normative grammars keep to the well-known traditional rule stating that the nouns denoting male beings should be classed as masculines, those denoting female beings as feminines, and those referring to inanimate objects as neuters" (ibid.:189). A look at modern reference grammars reveals that this traditional approach is stronger than common sense. Gender has always been described as a formal category of English, but far removed from a true gender language.
\end{abstract}

\section{An overview of gender in animals in modern reference grammars}

Most grammars tell us that the appropriate pronoun to use when referring to an animal is $i$, except for cases where the sex of the animal is known.

The most comprehensive grammar book often used by Czech students "Mluvnice současné angličtiny na pozadí češtiny" (2006) by L. Dušková et.al. puts in contrast the categories of gender in Czech and English. The authors provide us with examples of how gender is expressed with animal nouns in English.

Dušková et al. stress the difference between the primarily grammatical category of gender in Czech with limited semantic base and the primarily semantic gender category in English. Most animal nouns do not distinguish the gender and are referred to by it. The usage of this pronoun is typical of scientific texts and literature: "The cat flung itself across the yard. The fish produced every trick to detach itself from its tormentor" (2006:86). But Dušková points out that "the use of he or she does not necessarily express the sex, e.g. a fisherman speaks about a big fish as he, about whales as she.” According to Dušková, in these cases ,the only relative pronoun used is which" (2006:86). This is in contrast with English materials and grammar books, for example Greenbaum and Quirk (1993).

According to Dušková (2006), persons of masculine sex are masculine, persons of feminine sex are feminine and inanimates and animals are neuter. Higher animals stay somewhere between the persons and inanimates. Stylistic and emotive factors can cause exceptions from the basic classification. 
A more general description of the categories of gender can be found in Anglická mluvnice (1975) by Karel Hais.

Hais (1975:62) notes that animal names do not distinguish the gender and they are referred to by it. Only domestic animals and pets that are useful to people are referred to according to their sex. More formal gender distinction appears in higher animals (dog-bitch, cat- tomcat, bull-cow, stallion- mare, gander- goose, lionlioness, he-goat- she-goat, etc.) Lower animals are referred to by it (snake). According to Hais (1975:62) the animals which "are in contact with human beings are of masculine gender (dog, horse, canary) or of feminine gender (cat, parrot, fish)."

Dušková (2006:82-87) and Hais (1975:59-62) distinguish two main groups:

- The first group is formed by pairs expressed by different lexical items, such as: bull-cow, cock- hen, mare-colt-filly, drake-duck, fox-vixen

- The second group is formed by the pairs of animals of opposite sex which are distinguished by word formative processes:

$\circ$ by suffixes: lion- lioness, tiger- tigress

o by compound words: wolf-she-wolf, he-goat and billy goat ( or he-goat)-

she- goat ( or nanny-goat), turkey-cock- turkey-hen, tom- cat-pussy-cat

The most comprehensive explanations concerning the gender of animals can be found in Huddleston and Pullum's Cambridge Grammar of the English Language (2002). The authors distinguish the degree to which gender is "grammaticalised" in English (on the problem of "grammaticalization", cf. Hopper and Traugott 1993). They contend (2002:485) that "while pronoun choice depends on the meaning or reference of the antecedent there are places where the linguistic form of the antecedent restricts the choice of the pronoun." The author compares the following pair of examples:

a. The dog has lost his/its bone b. Fido has lost his/*its bone

According to the author the male animal mentioned above could be referred to by both The dog and Fido, "but the fact that the latter has a proper noun as head excludes the use of neuter pronoun it that is found as an alternative to he in $a$." (ibid.:485). He compares this situation to that with human babies.

Animals are treated as non-humans. The book provides us with these examples:

- $\quad$ The bull turned his/its head.

- $\quad$ The cow was lying on her/its back.

- $\quad$ The dog looked as if he/she/it needed a good brush.

The sentences above show that the meaning of it does not mean "neither male nor female". The authors claim that in many cases the neuter pronoun is used because the speaker does not know what the sex of the animal is.

According to the authors, the difference between it and he or she does not lie in the referent itself: "it is a matter of whether the speaker chooses to encode the sex of the referent. Encoding of sex in the antecedent does not require that it also be encoded in the pronoun." (ibid.: 489).

To sum up, the use of feminine and masculine in the case of animal antecedents is more likely with pets and domestic animals. Apart from distinguishing these two categories, Huddleston et al. mention creatures ranking high in the kingdom of wild animals (such as lions, tigers, elephants, etc.). They also mention the importance of "greater degree of interest in or empathy" with the animal (on the issue of sociopragmatic gender studies, cf. Mathiot and Roberts 1979). The animal is thus referred to by he or she. The use of masculine and feminine is even more obligatory if the animal is referred to by a proper name (ibid.:489). As will be shown in Chapter 4, the analysis from National Geographic confirms this observation.

The authors also distinguish three groups of dual- gender nouns: 
- Dual-gender masculine/neuter nouns, containing mainly farm animals such as

bull, cock, gander, he-goat, ram, stallion, tom-cat

- Dual-gender feminine/neuter nouns. This group contains predominantly names for the female animals and female kinship terms connected with those in the first group.

Cow, hen, lioness, mare, she-goat

- Triple-gender nouns represent the terms denoting animals without specification of sex.

Blackbird, dog, elephant, frog, goat, horse, lion, octopus, snake

Masculine and feminine are generally less likely to be used for lower animals except pets.

Longman's Grammar of Spoken and Written English (Biber et al. 1999) offers an approach to gender in animals. The authors pay attention to spoken language and consider gender "a less important category in English than in many other languages" (Biber et al.1999:311)

The authors distinguish two main gender classes: personal and non-personal:

\begin{tabular}{cll} 
& example noun & pronoun \\
\hline $\begin{array}{c}\text { personal/human: } \\
\text { masculine }\end{array}$ & Tom, a boy, the man & he \\
feminine & Sue, a girl, the woman & she \\
dual & a journalist, the doctor & he, she \\
non-personal/neuter: & a house, a bird & it \\
\hline
\end{tabular}

Figure 1: Gender classes in Biber (Biber et al. 1999: 311f)

Animals (pets in particular, ibid.:318) fall into the category of a three-way choice (personal he, she and non-personal it).

Longman English Grammar (1988:49-50) by L. G. Alexander offers very limited information on the gender of animals.

Alexander identifies the masculine and feminine of animal nouns by:

- "contrasting nouns describing animals ( normally replaceable by "it")

bull- cow, cock( or rooster)- hen, dog- bitch, gander- goose, pig- sow,ramewe, stallion- mare"

- "-ess endings and other forms indicating sex/ gender":

leopard-leopardess, lion-lioness, tiger-tigress

- "- the stressed prefix he-/ she- he- goat/ she- goat, he- wolf/ she- wolf".

Clearly arranged explanations concerning the gender of animals can be found in Quirk et al. (1985). The authors divide animal names into two categories: higher and lower animals.

- Higher animals

Male/ female gender distinctions in animal nouns are maintained by people with special concern (for example with pets, eg: cock and rooster for the male (with which- he/it or who- he coreference and hen for female (with which- she/it or who-she coreference (Quirk et al.1985:317)

Quirk et al. give other examples: 
Buck-doe, bull-cow, dog-bitch, gander- goose, lion- lioness, ram-ewe, stallion- mare, tiger-tigress.

In general, in nonexpert contexts there is no need to make a gender distinction, such as dog-bitch, stallion-mare. We can then use one term to cover both sexes, as in the case of $d o g$ and lion, or use a different term, eg: horse to cover both stallion and mare.(ibid.:317)

- Lower animals

Lower animals (eg: beetle, butterfly, snake, toad, tadpole) have which and it as pronouns. However, lower animals may also be viewed as higher animals. Thus we may speak of 'goldfish who swim around', 'bees who are busy', etc.

Sex differences can be indicated by a range of gender markers for any animate noun where they are felt to be relevant, eg: male-female frog.

The book provides us with the following examples: buck-rabbit doe-rabbit, cock- pheasant $\sim$ hen- pheasant, dog-fox bitch-fox, he-goat $\sim$ she-goat, roe-buck $\sim$ roedoe.

According to the authors, some animals require finer gender distinctions in language than others. This can be attributed to a number of factors. Laymen normally have no knowledge about the sex of animals like ant, herring, snake, spider; or, even if they do, it may not be a fact that they want or need to indicate. He and she are only likely to be used for animals with which man, "the speaking animal", has the closest connections- with the domesticated animals.

Quirk et al. distinguish nine gender classes. Three of them concern animal nouns (higher male animal, higher female animal and lower animal) as illustrated in the scheme below (ibid.:314):

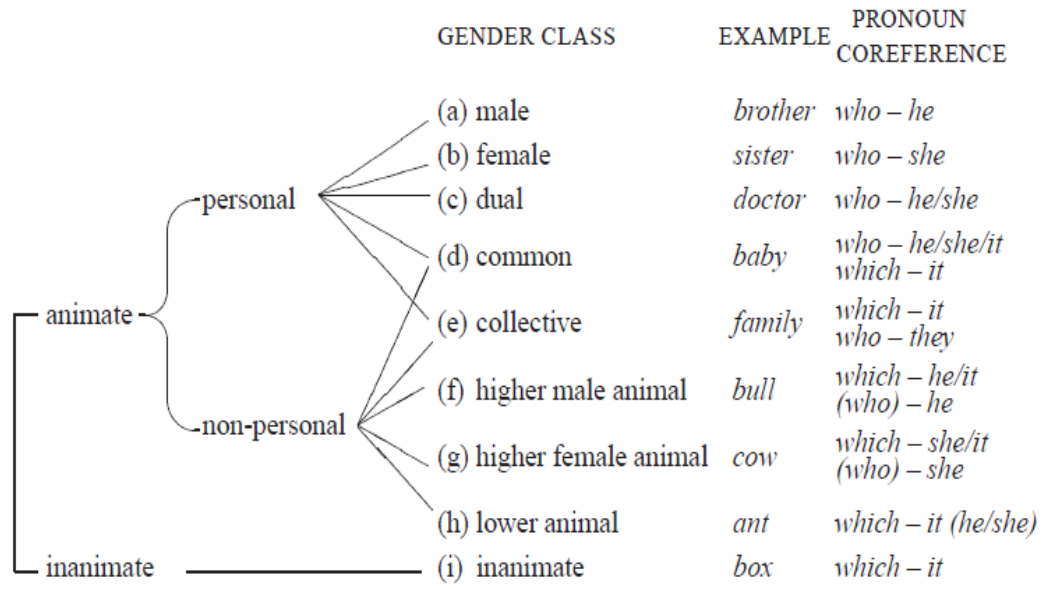

Figure 2: Gender system according to Quirk (Quirk et al. 1985: 314)

A very similar classification of nouns referring to animals is presented in Greenbaum, S. -R. Quirk: A Student's Grammar of the English Language (1993). The animals are divided into two main groups- familiar and less familiar animals. The following scheme distinguishes two main gender classes of animals: 


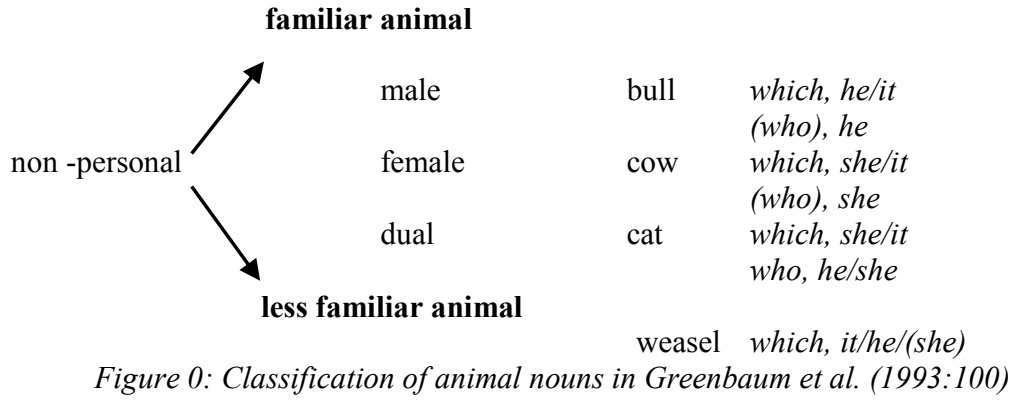

The above scheme differs from the one offered in Quirk et al. (1985) in that it introduces one additional category and it is dual gender of animals. In spite of the fact that there exist pairs like bull and cow, ram and ewe, hen and cock, dog and bitch, one member of the pair is used with dual gender.

Less familiar animals constitute the majority of animals, they are treated as inanimate and are referred to by it but they may be referred to as he or she as well.

To sum up, in discussing gender of animals more attention in grammar books is given to the word-formative processes or lexical items distinguishing heteronymous animal pairs than to the ways of assigning gender to unmarked nouns. Most grammars, not very clearly, divide animals into familiar, less familiar or higher and lower animals. According to the majority of grammars animals are treated as inanimates and thus referred to by it. This gender system may look confusing to speakers of English. The authors pay attention mainly to terminological differentiation, professional language use and gender assignment, mainly in written English. Most authors do not mention spoken reality when referring to animals. Only in more comprehensive grammars other factors of animal gender assignment are mentioned, namely:

- greater degree of interest in and empathy with the animal

- its position in the kingdom of wild animals

- emotional factors, tradition and convention

To mention a few reference books dealing with recent descriptions of gender assignment in animal nouns, modern views on the existence of the category of gender can be found in Vachek (1964), whose criteria for assigning gender are in agreement with the factors that are identified as crucial in my previous analyses (Zemková 2011). Although the respective authors base their studies on a variety of different corpora, such as children's literature (MacKay and Konishi 1980), children's stories (Prčíková 1999), web pages devoted to animal keeping and breeding (Vomlela 2002) and students' use of personal pronouns in tag questions (Marcoux 1973), the major results of my research are rather unexpected. As all of the authors found a surprisingly high number of "human" pronouns used to refer to animals, they claim that masculine is the prevailing gender. The findings offered by valuable authors can be summarized as follows:

- The choice of pronouns referring to animals is affected by a number of emotive factors and by the degree of personal involvement.

- The cut-off point within the class of animals differs from speaker (or author) to speaker depending on their professions, environment, etc.

- When referring to animal nouns, neuter pronouns are the least frequently occurring forms, while the masculine dominates. 


\section{The analysis of gender of animals based on National Geographic articles}

The corpus for this analysis includes all National Geographic articles concerning animal species published between 1979 and 2014. As a life-member of National Geographic Society since 1979 I own the 35 years' collection of this magazine. Taking into account my degree in biology, the theme of this analysis seemed to provide an interesting field for exploration in gender studies.

The objectives of this analysis were to find out the rules and principles of gender assignment for animal nouns in the articles. I recorded all animal nouns with their gender references, which means all personal, possessive and reflexive pronouns referring to animal nouns in the corpus. Animals without gender references were not listed.

The animals are divided into classes and species, starting with the lowest insect species and finishing with big mammals. The results of the analysis of each partial animal group are given in a separate chart.

\subsection{Insect}

The insect species are divided into two parts. The first part covers the ant species, which belong to the most frequently mentioned insects in the corpus. The second part includes the rest of insect species, retrieved from the corpus.

\section{Ant species}

\section{Material analysis}

10 ant species were referred to by a total of 132 pronominal pronouns. The dominant gender was feminine $-86.4 \%$ of all pronouns, only $3.8 \%$ masculine and $9.8 \%$ neuter. The dominance of feminine gender may be explained by the social life of this animal.

Ant colonies are female societies, where all workers are female. Consequently the ant world is a mother-and-daughter universe (National Geographic July 1995). In general, the ant itself is mostly viewed as she. Even the headline of one of the main articles concerning ants "The Ant and Her World" (National Geographic June 1984, p.775) is supported by this hypothesis.

Generally other genders in ant colony are marginal. The dominance of feminine pronouns in the insect species is closely connected with parental care, particularly the relationship between mother and her young. Authors use expressions as a young, a newborn, offspring, a hatchling, a baby and grandchildren to express youngsters. This can be documented by the following example describing maternal care in the earwig:

(1) After eggs hatch, the female earwig watches over her young for as long as four weeks. The hatchlings use their mother as chicks do a brooding hen, scapering beneath her body at the slightest sign of danger.

(National Geographic August 1980, p.284)

The neuter gender assignment is marginal. Only 25 neuter pronouns were found, referring to the description of life cycle and three neuter pronouns referring to youngsters. Although authors use the neuter forms when describing the life cycle and behaviour of these individuals, their personal interest is apparent.

\section{Insect - Final Chart}

\begin{tabular}{|c|c|c|c|}
\hline Masculine: & 22 & $=$ & $8.3 \%$ \\
\hline Feminine: & 207 & $=$ & $77.5 \%$ \\
\hline Neuter: & 38 & $=$ & $13.6 \%$ \\
\hline Total: & 267 & $=$ & $\begin{array}{r}100 \% \\
115\end{array}$ \\
\hline
\end{tabular}




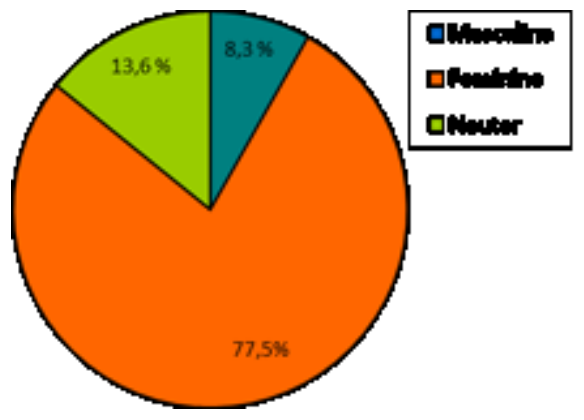

Figure 0: Final chart - Insect

Having finished the counts, in the world of the insect the feminine gender is dominant. The explanation of this fact is simple. The female plays the main role in the reproductive process, egg laying and maternal care. That is the reason, why authors pay attention predominantly females in $77.5 \%$ of all retrieved examples.

\subsection{Sea Species}

The authors distinguish the masculine or feminine gender in $25 \%$ of the excerpted samples of the marine species. The marking of masculine and feminine gender is balanced- $12.5 \%$ of all pronouns were masculine, $12.5 \%$ feminine. The balance may result from parental roles of these animals.

Surprisingly, that in such a "low" animal as squid, cuttlefish or jellyfish the authors distinguish the gender. Even if these species belong to low biological classes of Cephalopoda, Scyphozoa and Malacostraca, the gender distinction is not parallel with the biological classification. The authors thus view them as higher animals.

This fact is evident in the description of mating process in the squid as described in the following example:

(2) A red-armed male embraces a female after mating. She will lay more than 50,000 eggs.

(National Geographic August 2004, p.40)

In the case of fish species the use of neuter gender is dominant $-75 \%$ of all pronouns were neuter. While the majority of animal species play only one role (masculine or feminine), some are described in two or three roles.

I have excerpted 44 tropical fish species. Many of them have very special social structure, mating process and parental care. This is the main reason why authors distinguish the gender roles when referring to the specific fish species

The authors also use feminine and masculine gender in the descriptions of parental care, in which both "parents" play important roles. The example below describes the parental care of Flag benny species, where "the father blenny" -as the authors name him - plays a very important role in the protection of his young:

(3) I sit back and wait for him to settle down in his new home. Thirty minutes pass before he takes on the job of wriggling his body over the eggs to aerate and clean them. While the father blenny protects the eggs, I reset the camera for a new series of shots.

(National Geographic July 1992, p.107) 
To sum up, the role of both male and female marine fish in parental and mating process is remarkably balanced and similarly balanced is the distribution of masculine and feminine gender marking $-12.2 \%$ and $12.7 \%$ respectively.

Instead of the description of reproductive processes and parental care, the authors distinguish the gender roles when describing the life cycle and observation of marine fishes. The occurrence of neuter pronouns in marine fishes is high. $73.9 \%$ of the retrieved gender markers are neuter. They are connected with the description of the life cycle, observation and youngsters.

\section{Sea Species - Final chart}

All marine species mentioned above were referred to by a total of 568 pronominal pronouns as follows:

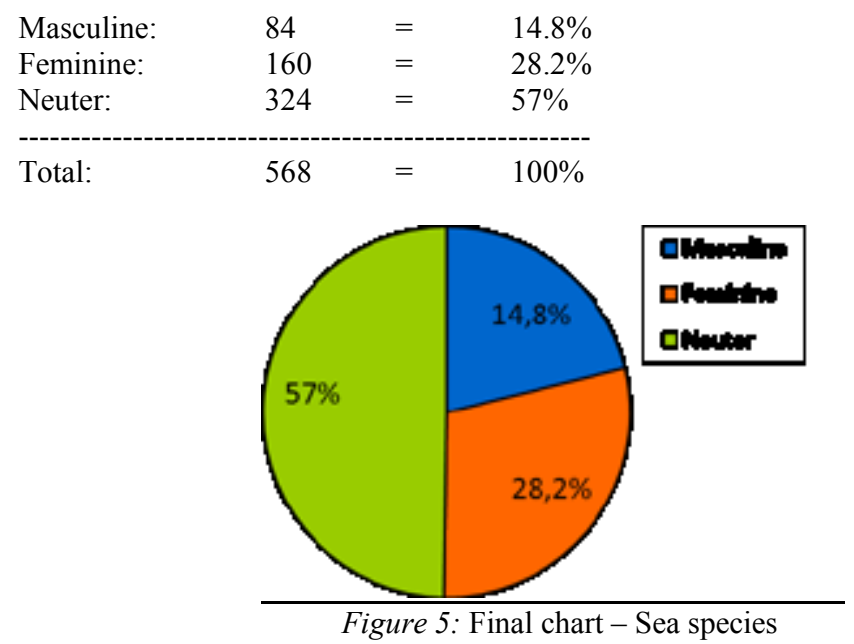

The above chart shows the balanced occurrence of definite and indefinite pronouns when referring to all retrieved marine species.

The animals with the lowest occurrence of definite pronouns were those belonging to the marine microfauna. The jellyfish was the only animal referred only to by neuter. The prevalence of neuter gender markers is visible in fishes (73.9\% pronouns). Only one third of retrieved marine fishes has been marked with he or she. More than a half of neuter markers has been found in shark species. On the other hand, whale and orca species belong to marine animals with the prevalence of feminine and masculine pronouns. The only marine individual with the absence of the neuter form was the sea horse. To sum up, the marine species are viewed predominantly as he or she.

\subsection{Reptiles and Amphibians}

\section{Material analysis:}

The lizard, snake, turtle and frog species were referred to by a total of 226 pronominal pronouns as follows:

\begin{tabular}{llll} 
Masculine: & 32 & $=$ & $14.2 \%$ \\
Feminine: & 110 & $=$ & $48.7 \%$ \\
Neuter: & 84 & $=$ & $37.2 \%$ \\
\hline------------- \\
Total: & 226 & $=$ & $100 \%$
\end{tabular}




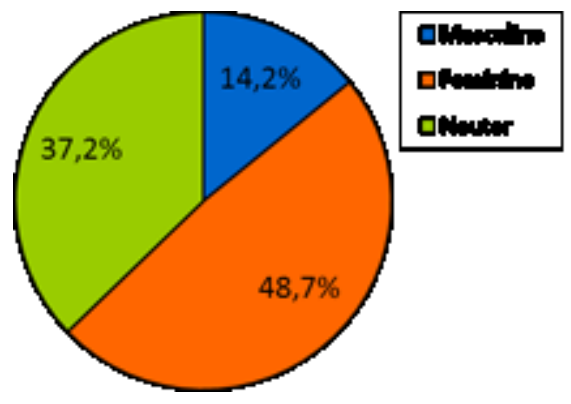

Figure 6: Distribution of gender - Reptiles and Amphibians

In this part I have put together two biological classes- Reptiles and Amphibians. species.

Reptiles include the lizard, snake and turtle species, amphibians covers frog

I have found 21 species of reptiles and 10 species of amphibians. The number of articles concerning snake and lizard species was lower in comparison with the articles about turtles and frogs. Turtle and frog species belong to frequently mentioned animals in the corpus.

From the above data the preference of feminine gender in these two classes is high $-48.7 \%$ of all excerpted pronouns are feminine.

In snake and lizard species the occurrence of feminine markers is connected with the observation. The next example shows the life story of the studied female snake. The researchers marked her with number and studied this individual for years:

(4) Number 38 had weighed 82 grams and measured 52 centimetres long in 1978 when her two-segment rattle showed her to be a yearling. She measured 92 centimeters in length and might be ready to produce young. I gently passed my thumb along her abdomen but felt no lumps. She lacked

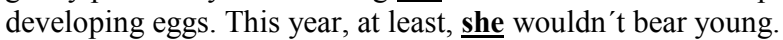

The saga of number $\mathbf{3 8}$ reached a climax in 1986, when I captured her for the third time and found her pregnant in her tenth year...

(National Geographic July 1987, p.131)

The occurrence of masculine markers in snakes and lizards is very low. The preference for the feminine in turtles and frogs is closely connected with the main role of females in reproductive process and maternal care. Even if these species belong to different classes according to biological classification, the gender assignment principles are very similar. It is the female, which is most important in reproductive process and eggs laying both in turtles and frogs. Therefore it is the female, which is studied in the majority of retrieved examples and assigned to as she. In frogs a great diversity of parental behaviours have been excerpted. Amphibians create the most interesting range of parental care I have discovered. This could be the reason of the highest feminine and masculine gender occurrence within these two biological classes. The animals are referred to with the personal interest of the researchers. They use the terms father, dad, mother when describing variety of behaviours. Even for the frog youngsters the authors use variety of expressions as tadpole, toadlet, froglet and young. In the following example the male takes care about his froglets.

The authors surprisingly have not used neuter as a dominant gender in reptiles and amphibians. The neuter has been mainly used for general descriptions of life 
cycle, diet and observation. The highest occurrence of neuter markers has been found in lizards while the lowest were among frogs.

\subsection{Birds}

In the class of birds I have found 20 species with gender distinctions. I have divided this class into two main groups: Birds of prey and Exotic birds.

I have excerpted Eagle, Goshawk and Owl species, which belong to birds of prey. All articles concerning birds of prey describe the life of these birds, their training for special purposes such as hunting and the personal attitudes, experience and exploration of the researchers.

The eagle was the most frequent species of bird in the articles. I have found three eagle genera (Sea, Harpy and Philippine Eagle), all of them with gender distinctions. The dominance of articles concerning this bird may result from the fact, that eagles together with other birds of prey belong to the endangered species. Moreover, the eagle plays an important culture role as the national symbol of many nations. Consequently majority of retrieved examples refer to observation of these endangered individuals. Both males and females have been observed. All studied individuals are referred to by he or she. The neuter in birds of prey is marginal, for it covers only $10.5 \%$ of retrieved pronouns. They refer to parental care and nesting, the life cycle and observation. In the case of such specific and endangered species there is no need to use neuter gender markers. Generally the authors prefer more personal and emotive $\boldsymbol{h} \boldsymbol{e}$ and she when referring to these birds.

The quantitative analysis has revealed that the dominant gender in the second group of birds is masculine $-56.7 \%$ of all pronouns. The number of neuter pronouns is higher in "exotic birds" in the comparison with birds of prey.

The low occurrence of the neuter in exotic birds could be connected with their exotic origin. The majority of these birds are very rare and threatened with extinction. Consequently, they require finer gender distinction. The examples could be given of New Zealand's "exotic birds" such as kiwis, kakapos and snared crested penguins, which belong to the specific group.

To sum up, the gender distinction in this group of birds is very common. Instead of gender markers, authors use expressions, which are specific for birds:

(5) I was helping weigh a three-year-old female kakapo caller Aranga. (All kakapos have names, many of them suggested by New Zealand children. Aranga means "resurrection".) She used her beak as an ice ax and her toes as crampons. As she nibbled the sweet potato I was using to coax her onto the scale, I felt the tickle of her whiskers and the warmth of her down. When the food was gone and Aranga looked up with her inquisitive owl-like face, I had to laugh.

(National Geographic October 2002, p.83)

\section{Birds - Final chart}

All above mentioned bird species were referred to by a total of 383 pronominal pronouns as follows:

$\begin{array}{llll}\text { Masculine: } & 209 & = & 54.6 \% \\ \text { Feminine: } & 93 & = & 24.3 \% \\ \text { Neuter: } & 81 & = & 21.1 \% \\ ------------ \\ \text { Total: } & 383 & = & 100 \%\end{array}$




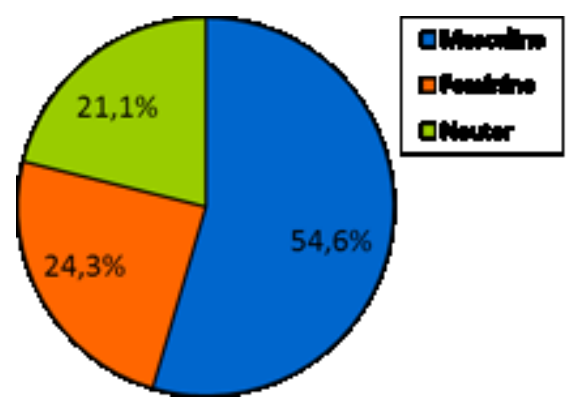

Figure 7: Final chart - Birds

To sum up, the dominant gender in assigning birds is masculine. It dominates especially in the descriptions of wide range of birds' behaviours and life cycle.

\subsection{Big cats}

The next group of animals, which has been frequently mentioned in the National Geographic corpus, belongs to the family of "Big Cats". This group includes the four main species of cat in the genus of panthera- the lion, tiger, leopard and jaguar, which are quite similar both in behaviour and structure (National Geographic October 2001). I have paid attention to gender distinctions in the most frequently -mentioned big cats in the corpus- lion, tiger and leopard and their subspecies. I found no gender references concerning the jaguar.

\section{Big cats- Final chart}

The three species of big cats were referred to by a total of 450 pronominal pronouns as follows:

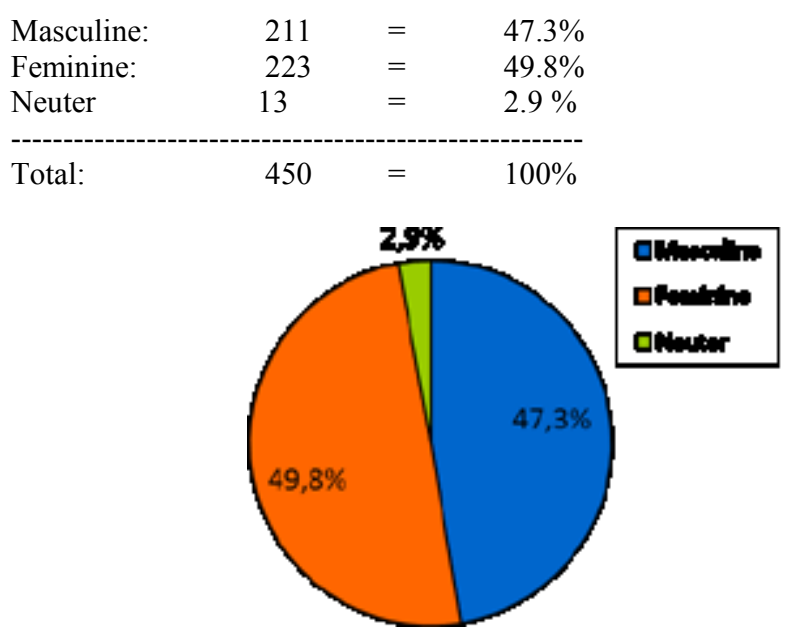

Figure 8: Final chart - Big cats

From the data above, the usage of the feminine and masculine gender markers are balanced. The most important factor that influences gender assignment in big cats is that of emotion. The majority of excerpted examples shows both emotive factor and 
personal interest. The researchers and authors of the articles "feel" with these species of big cats and they talk about all of them, including youngsters, as a "he" or "she". The majority of adult animals and cubs have names, in one case a number. They personalise their animals and talk about their "loved pets" or "friends". The explanation for this practice is related to the fact that these big cats belong to the threatened species and are among the most recognizable and popular of the world's megafauna. The most frequently mentioned and personalised big cat in my corpus has been a tiger. The authors consider him the most charismatic animal in the world. He is the national animal of several Asian nations.(National Geographic December 1984)

The occurrence of neuter pronouns is very low, making up only $2.9 \%$ of all pronoun markers. The authors have used neuter in the general descriptions of the life cycle of the subspecies and in two cases the lion's cub was referred to by it.

\subsection{Bear}

\section{Material analysis:}

Bears were referred to by a total of 254 pronominal pronouns as follows:

$\begin{array}{llll}\text { Masculine: } & 77 & = & 30.3 \% \\ \text { Feminine: } & 167 & = & 65.8 \% \\ \text { Neuter: } & 10 & = & 3,9 \% \\ --------------------- \\ \text { Total: } & 254 & = & 100 \%\end{array}$

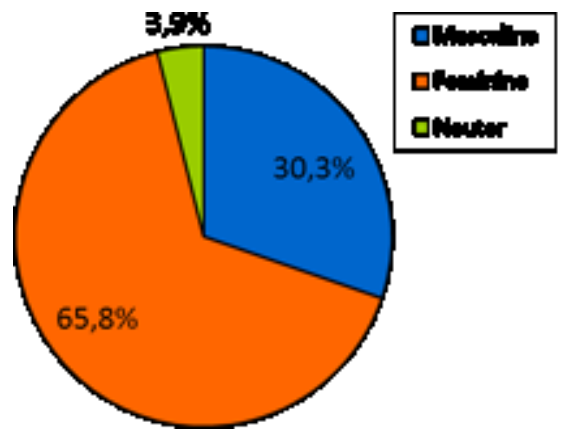

Figure 9: Distribution of gender - Bear

This group has been distinguished into two main families retrieved from the corpus covering eight bear and two panda species.

As can be seen from the chart, feminine and masculine pronouns have been used the most frequently. In the majority of the retrieved articles bears have names and they are always viewed as he or she. The authors have marked bears as he-bear and she-bear:

(6) "The she-bear drops back onto her front feet, walks across the snow".

(National Geographic July 1979, p.125)

The dominance of the feminine gender can be seen in most of the articles. They make up in total $65.8 \%$ of all pronouns. This could be a result of the fact that majority of retrieved examples describe the relationship between the mother and her cub or cubs. In all of examples cited below, the personal interest plays very important role. The authors thus speak about mother bear and mum when describing the relationship: 
(7) "A cub peeks around a drift as its twin and mother relax. The cubs are about three months old. Mom is leading her playful clan to the frozen bay where she' 11 hunt.

(National Geographic February 2004, p.45)

The usage of gender markers is strongly influenced by the behaviour of these animals. Bears are typically solitary animals with the exceptions of courting individuals and mothers with their young. Consequently a number of the articles describe the life cycle of the individuals, especially concerning observing food and diet. In the case of pandas, especially the species of Giant Pandas, the feminine and masculine gender distinctions are the most frequent. The most likely explanation is that the Panda is an endangered species and highly threatened. (National Geographic July 2006). This is the reason for very low occurrence of neuter. I have found only eight neuter pronouns concerning the general description of their life cycle and diet.

\subsection{Elephant}

\section{Material analysis:}

The two species of elephants were referred to by a total of 309 pronominal pronouns as follows:

\begin{tabular}{llll} 
Masculine: & 99 & $=$ & $31.9 \%$ \\
Feminine: & 210 & $=$ & $68.1 \%$ \\
Neuter: & 0 & $=$ & $0 \%$ \\
\hline------------- \\
Total: & 309 & $=$ & $100 \%$
\end{tabular}

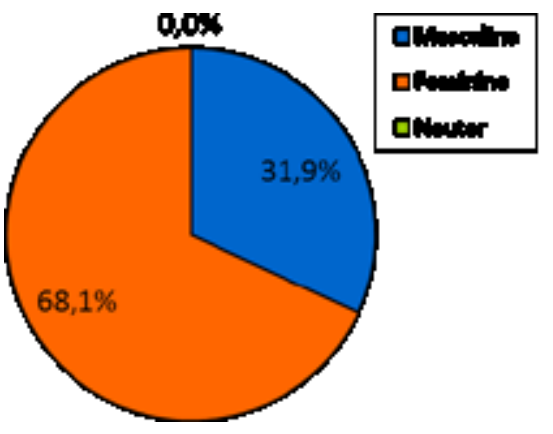

Figure 10: Distribution of gender - Elephant

This largest land animal belongs to frequently-occurring species in National Geographic. Out of the three living species I have excerpted African Forest Elephant and Asian Elephant. A quantitative analysis has revealed that the dominant gender was feminine. The highest occurrence of feminine gender markers within the corpus could be explained by the specific life cycle of this animal. Elephants live in a structured social order. The females live in family groups made up of mothers, daughters, sisters and aunts. These families are led by the matriarch, the eldest female. The members of the groups are referred to by feminine in all excerpted examples:

(10) [G.32.] Babylon is the quintessential matriarch, with a hole in her left ear and a half century of experience and knowledge in her head. Yet she's still a new mother as well as a grandmother, followed closely by $\underline{\text { her }}$ 
own tiny calf, and her daughter's, and a third. Another member of the Biblical Towns, Babel, badly lame manages to survive and stay with the family because Babylon waits for her.

(National Geographic September 2008, p.52)

The authors have also paid attention to the descriptions of maternal care and breeding of the calves. The researchers personalise the mothers and calves and give them names. I have found no neuter gender markers

\subsection{Apes}

\section{Material analysis:}

The eight species of apes were referred to by a total of 332 pronominal pronouns as follows:

\begin{tabular}{llll} 
Masculine: & 164 & $=$ & $49.5 \%$ \\
Feminine: & 158 & $=$ & $47.5 \%$ \\
Neuter: & 10 & $=$ & $3 \%$ \\
\hline--------------------------------------- \\
Total: & $332=$ & $100 \%$
\end{tabular}

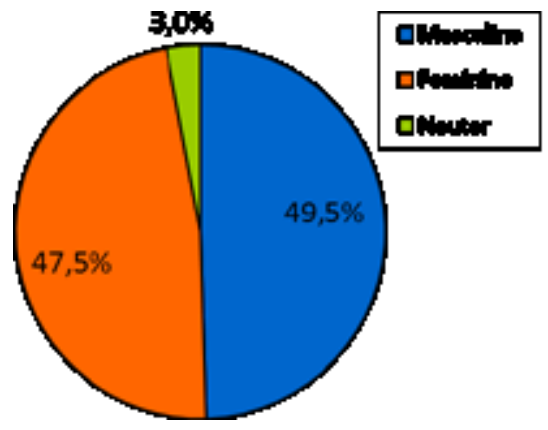

Figure 11: Distribution of gender - Apes

Out of eight species of apes, three of them were prevalent. Majority of articles described mainly the Gorilla, Orangutan and Chimpanzee species.

The analysis has revealed that both feminine and masculine genders are dominant. The neuter is marginal. I have excerpted only eight neuter pronouns, all of them concerning juveniles.

The majority of retrieved examples describe the behaviour and social structure of different species. These studies have shown that in their natural environments, the different apes display varying social roles. The most frequent are descriptions of families:

(8) "Banging the cans to intimidate larger males, he bluffed his way to the top. Passion killed and ate Gilka's infant, Otta, sharing the flesh with $\underline{\text { her }}$ daughter, Pom. Figan's status as the alpha male had been bolstered by $\underline{\underline{\mathbf{h i s}}}$ close relationship with his brother Faben. When faben disappeared, Figan had a hard time fending off challengers by himself- although he managed to reign for ten years. After three-year-old Mel's mother died of pneumonia, he was adopted by an adolescent male."

(National Geographic December 1995, p.110,111) 
The close relationship between studied apes and the authors is evident. The animals are divided into study groups and majority of the individuals have names, nicknames or marks, including the youngsters:

(9) "Families are headed by females like Theodora, here with her black infant, its playmate, and a male friend, Pinocchio. Closest to me huddled Thea and baby Thistle, with oldest daughter Theodora and her infant, Teleki."

(National Geographic November 1987, p.677)

In majority of these research studies a very strong relationship is obvious between the mother and her juveniles.

To sum up, the most significant factor that influences the gender assignment in apes is that of emotion. All the animals are referred to with personal interest. The researchers personalise the animals and talk of them as $\boldsymbol{h} \boldsymbol{e}$ and she.

\subsection{Final chart and material analysis}

All analysed species taken from zoological articles of the National Geographic have been referred to by a total of 2829 pronominal pronouns as follows:

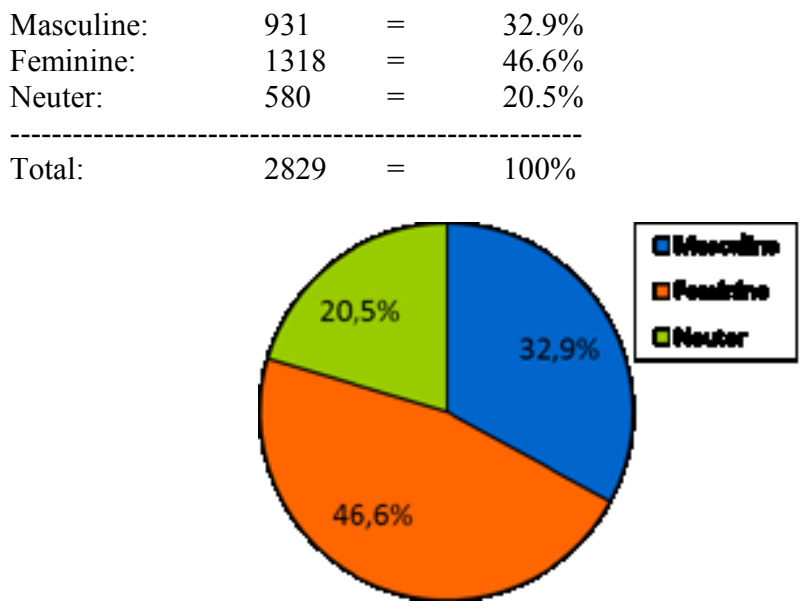

Figure 12: Final chart - National Geographic Material analysis

\section{Conclusion}

The analysis of all zoological articles revealed the prevalence of feminine gender markers in all animal species in question. The "lowest" animals with gender distinctions found in the corpus were insect species. On the other hand the "highest" animals from the point of view of zoological hierarchy were apes. Out of 2,829 pronominal pronouns $46.6 \%$ of all pronouns were feminine, $32.9 \%$ masculine and $20.5 \%$ neuter. Surprisingly, the highest occurrence of feminine pronouns was recorded in ant species. This fact could be explained by the specific social life cycles of these insects. The other species with the dominance of feminine in their gender assignment were bears $(65.8 \%)$, lions $(58.9 \%)$, tigers $(53.2 \%)$, reptiles and amphibians $(48.7 \%)$ and whales $(45.6 \%)$. Feminine was predominantly used in 
situations describing maternal care and reproduction. Masculine prevalence occurred in seahorse species $(74.4 \%)$, exotic birds $(56.7 \%)$, birds of prey $(53.1 \%)$, leopards $(52.9 \%)$ and apes $(49.5 \%)$. The predominance of masculine gender is probably the result of extensive descriptions of behaviours, life cycles and reproduction processes, in which the biological gender plays a significant role.

The neuter proved to be a surprisingly marginal category. It is the most frequent gender when referring to marine microfauna (75\%), tropical fishes $(73.9 \%)$ and shark species $(53.7 \%)$. The possible explanation of the neuter gender prevalence might be the wide variety of microfauna and fish species. The authors had no need to indicate the sex of the animals. General descriptions of life cycle prevailed. On the other hand, neuter was totally absent from descriptions of tiger, elephant and seahorse species. The explanation of this fact is simple; strong personal involvement in the case of the endangered tiger and elephant and the unique reproductive process of the seahorse.

Concluding from the authentic data, the assignment of gender to animal nouns in National Geographic articles does not fully follow the rules of semantic assignment system. Even though the majority of animal species are assigned to genders according to their biological sex, there are other important factors that influence the gender marking. The choice of the pronoun also depends on the social roles of the animals and their status in "the animal kingdom". Many of the animals retrieved from National Geographic represent threatened species and are among the most recognizable and popular of the world's megafauna. A good example could be "the big cat" species, such as jaguar, leopard and tiger, "the most charismatic animal" (cited from National Geographic 1984:763) in my corpus. Tigers are personalised, have names and are referred to entirely by he or she. Huddleston and Pullum's statement that he and she are "more likely with the creatures ranked high in the kingdom of wild animals (e.g. lions, tigers, elephants)" (Huddleston et al. 2000:489) is very much in agreement with my own observations. The distinction between higher and lower animals as it occurs in National Geographic does not necessarily correspond to the biological classification, so lower animals are very often viewed as higher animals.

Apart from their grammatical functions, the pronouns imply a sociological function. Although the corpus was based on zoological articles and the biological sex of the individuals concerned played an important role, the findings of my research confirm Vachek's observation that "feminine or masculine reference signals some interest of the speaker in the individual referred to. There may be some interference of emotional factors" (Vachek 1964:191).

Comparing my conclusions with the recent works surveyed in the introductory part, feminine prevails in my corpus while all the other authors contend that the masculine gender is dominant. Based both on my own study and on other recent studies in the area of assigning gender to animals, the following conclusion can be drawn, providing an answer to the original question: "How is gender assigned to animal nouns in English?" When referring to animal nouns, neuter pronouns are the least frequently occurring forms. Surprisingly, a significant role in the choice of pronouns referring to animals is played by emotional factors, personal involvement, biological classification, tradition and convention.

To sum up, the common claim that "the pronoun it is used to refer to animals predominantly in scientific or non-literary contexts where there is no need to express personal or social attitudes" is not universally valid.

\section{Bibliograpic references}

ALEXANDER, L.G. 1991. Longman English Grammar Practice. Longman -LEGP ALEXANDER, L.G. 1998. Longman English Grammar. Longman -LEG 
BIBER, D. - JOHANSSON, S. - LEECH, G. - CONRAD, S. - FINEGAN, E. 1999. Longman Grammar of Spoken and Written English. London: Longman.

BIBER, D. - CONRAD, S. - REPPEN, R. 1998. Corpus Linguistics. Investigating Language Structure and Use. Cambridge: Cambridge University Press.

CORBETT, G. 1991. Gender. Cambridge: Cambridge University Press.

CRYSTAL, D. 1995. The Cambridge Encyclopedia of the English Language. Cambridge: Cambridge University Press.

DUSKOVÁ, L. 2006. Mluvnice soucasne anglictiny na pozadi cestiny. Praha: Academia

HAIS, K. 1975. Anglicka mluvnice. Praha: SPN.

HOPPER, PAUL J. - CLOSS TRAUGOTT, E. 1993. Grammaticalization. Cambridge: CUP

HUDDLESTON, R.D. 1988. Introduction to the Grammar of English. Cambridge: Cambridge University Press.

HUDDLESTON, R.D. - PULLUM, G.K. 2002. The Cambridge Grammar of the English Language. Cambridge: Cambridge University Press.

HUDDLESTON, R. 1988. English Grammar: An Outline. Cambridge: Cambridge University Press

MACKAY, D. G. - KONISHI, T. 1980. Personification and the Pronoun Problem. Women's Studies International Quarterly 3: 149-163.

MARCOUX, D. R. 1973. Deviation in English Gender. American Speech 48: 98-107

MATHIOT, M. - ROBERTS, M. 1979. Sex roles as revealed through referential gender.in American English. In: Madeleine Mathiot (ed.), Ethnolinguistics Boas, Sapir and Wholf Revisited, The Hague; Mouton, 1-47. (Contributions to the Sociology of Language, 27).

PRCIKOVA, M. 1999. Gender and Animals. In: Acta Facultatis Universitatis Presoviensis. Spolecenskovedny zosit 18, 85-141. Prešov.

QUIRK, R. - GREENBAUM, S. - LEECH, G. - SVARTVIK, J. 1972. A Grammar of Contemporary English. London: Longman.

QUIRK, R. - GREENBAUM, S. - LEECH, G. - SVARTVIK, J. 1985. A Comprehensive Grammar of the English Language. London: Longman.

QUIRK, R. - GREENBAUM, S. 1973. A University Grammar of English. London: Longman.

VACHEK, J. 1964. Notes on Gender in Modern English. In: Sbornik praci filosoficke fakulty brnenske university A, 12:189-194.

VOMLELA, J. 2003. Gender and Animal Nouns in Selected Web Pages Devoted to Animal Keeping and Breeding. In Theory and Practice in English Studies. Volume I.

Proceedings from the Seventh Conference of English, American and Canadian Studies, ed. J. Chovanec, 137-142. Brno: Masarykova univerzita.

ZEMKOVA, L. 2011. The Analysis of Gender Markers in Animals. In Brno Studies in English, Brno, Masarykova univerzita. ISSN 0524-6881, 2011, vol. 201/37, no. 1, s. $127-134$.

Words: 6817

Characters: 42778 (23, 77 standard pages)

Mgr. Ludmila Zemková, Ph.D.

Department of English, Faculty of Education

University of South Bohemia

Jeronýmova 10, 37115 České Budějovice

Czech Republic

email: zemkova@pf.jcu.cz 